\title{
Internacionalização do ensino superior e línguas estrangeiras: evidências de um estudo de caso nos níveis micro, meso e macro
}

\author{
Gabriel Brito Amorim \\ Kyria Rebeca Finardi
}

Resumo: O estudo propõe uma reflexão sobre o processo de internacionalização das universidades brasileiras. Com esse fim, um estudo de caso foi realizado em uma universidade federal do sudeste com objetivo de analisar aspectos micro, meso e macro da internacionalização dentro de três esferas concêntricas, quais sejam: da comunidade acadêmica, da instituição e do governo. A análise é de cunho híbrido com dados quantitativos e qualitativos triangulando (1) percepções de alunos e professores sobre os impactos das ações de internacionalização na universidade investigada - nível micro; (2) as ações de internacionalização implementadas ou em fase de implementação nessa instituição - nível meso; e (3) as políticas linguísticas e de internacionalização propostas pelo governo por meio dos programas Ciências sem Fronteiras (CsF), Inglês sem Fronteiras e Idiomas sem Fronteiras (IsF) - nível macro. Resultados da análise macro sugerem que a internacionalização afeta e é afetada pela globalização onde o inglês tem um papel diferenciado dos outros idiomas. A análise meso sugere que a instituição investigada almeja a internacionalização que ainda é insipiente e marcada por desafios. Finalmente, a análise micro sugere que a comunidade acadêmica está interessada no processo de internacionalização ainda que não esteja plenamente engajada, talvez pela falta de sintonia entre os três níveis da política e ações de internacionalização. O estudo conclui que as línguas estrangeiras em geral e o inglês em particular são essenciais para o pleno desenvolvimento do processo de internacionalização que, conforme se pode perceber na análise dos programas $\mathrm{CsF}$ e IsF, ainda é limitado e desarticulado de políticas linguísticas e educacionais de base.

Palavras-chave: Inglês. Políticas linguísticas. Programas de internacionalização.

\section{Internationalization of higher education and foreign languages: evidence from a case study at}

\section{micro, meso and macro levels}

Abstract: The study proposes a reflection on the internationalization process of Brazilian universities through a case study carried out in a federal university in the southeast of Brazil to analyze the micro, meso and macro aspects of internationalization within three concentric spheres, namely: the academic community, the institution and the government. The analysis uses a mixed methods design with quantitative and qualitative data, triangulating (1) perceptions of students and teachers from a southeastern federal university on the impact of international actions in that university - micro level; (2) the internationalization actions implemented or under implementation in that institution - meso level; and (3) language policies and internationalization programs proposed by the government through the Science Without Borders (SwB), English Without Borders (EwB) and Languages without Borders (LwB) programs - macro level. Results from macro analysis suggest that internationalization affects and is affected by globalization where English has a distinctive role in regards to other foreign languages. Results of the meso analysis suggest that the institution investigated aims at internationalization that is still incipient and marked by challenges. Finally, results of the micro level analysis suggest that the academic community is interested in the process, but not yet fully engaged, perhaps due to the lack of convergence between the three levels of policies and internationalization programs and actions. The study concludes that foreign languages in general and English in particular are essential for the development of the internationalization process, as can be seen in the analysis of the SwB and the EwB programs, which suggest that internationalization is still out of tune with linguistic and educational policies in the base.

Key words: English. Language policies. Internationalization programs. 
Internacionalização do ensino superior e línguas estrangeiras: evidências de um estudo de caso nos níveis micro, meso e macro

\section{Introdução}

Leite e Genro (2012) discutem as imbricações entre os conceitos de hegemonia, imperialismo e globalização neoliberal que sustentam a compreensão da avaliação e internacionalização do ensino superior levantando evidências sobre a constituição e 'práticas' de um imperialismo benevolente com vistas à formação de uma zona comum de educação superior formada pela América Latina, Caribe e União Europeia. Segundo esses autores, podemos observar uma nova epistemologia da Educação Superior no século 21 que promove ações globais e internacionais na direção do capitalismo acadêmico, representado por acordos e instituições como a Resolução de Bologna que, segundo Bianchetti e Magalhães (2015) tem como objetivo prolongar o histórico prestígio que as instituições de ensino superior européias tiveram até começarem a ser ameaçadas pela hegemonia dos Estados Unidos.

Ainda sobre essa nova epistemologia da educação superior, Segrera (2015) identifica as tendências mundiais na universidade moderna, dentre as quais destacamos a massificação da educação, o crescimento do uso de tecnologias da informação e comunicação, o aumento da mobilidade acadêmica e a privatização das instituições de ensino superior. Todas essas tendências são afetadas pela globalização que segundo Altbach (2004 apud LUCE; FAGUNDES; GONZÁLES MEDIEL, 2016) se confunde com a internacionalização do ensino superior.

A globalização, definida como o fluxo de tecnologia, economia, conhecimento, pessoas, valores e ideias entre fronteiras (KNIGHT; de WIT, 1997) afeta e é afetada pela internacionalização da educação superior, definida como o processo de integração de uma dimensão internacional, intercultural e global na missão ou função da educação superior (KNIGHT, 2003, p. 2, nossa tradução) ${ }^{1}$.

Luce, Fagundes e González Mediel (2016) entendem que como a internacionalização do ensino superior impulsiona os sistemas e instituições de educação superior a responder às necessidades educativas do mundo globalizado, para os países em desenvolvimento, como o Brasil, investir na internacionalização da educação superior é incontestavelmente uma necessidade para a inserção no mundo globalizado. Nesse sentido, este estudo pretende dar uma contribuição analisando com uma determinada instituição de ensino superior investe na sua internacionalização.

\footnotetext{
${ }^{1}$ [Internationalization] is defined as the process of integrating an international, intercultural, or global dimension into the purpose, functions or delivery of postsecondary education.
} 
Importante se faz assinalar que a internacionalização não ocorre de maneira uniforme e igualitária em todos os contextos como nos lembram Lima e Maranhão (2009) na discussão da internacionalização ativa e passiva. Segundo esses autores a internacionalização ativa se dá quando as políticas de internacionalização apoiam a recepção de acadêmicos (mobilidade do tipo IN) e a oferta de serviços educacionais no exterior como a exportação e instalação de campi em outros países. Já a internacionalização passiva se caracteriza pela inexistência de uma política clara de internacionalização para o envio de alunos para outros países (mobilidade do tipo OUT), os quais não possuem recursos materiais e humanos para receber e oferecer este tipo de serviços educativos em seus países de origem.

Partindo do pressuposto de que a globalização cria tanto riqueza quanto pobreza (por exemplo, BLOMMAERT, 2010; FINARDI, 2016) e de que a internacionalização é uma consequência dela e da economia do conhecimento (VARGHESE, 2013) este estudo propõe uma reflexão sobre a internacionalização do ensino superior em um contexto de internacionalização passiva (LIMA; MARANHÃO, 2009). Para tanto, o estudo expande a proposta de análise em dois níveis (institucional e nacional) de Knight (2004), propondo uma análise em três níveis, quais sejam: o nível micro, operacionalizado neste estudo como as percepções de alunos e professores de uma universidade federal do sudeste brasileiro sobre os impactos das ações de internacionalização nessa universidade; o nível meso, entendido como as ações de internacionalização implementadas ou em fase de implementação na instituição investigada, e o nível macro, entendido como as políticas linguísticas e de internacionalização propostas pelo governo por meio dos programas Ciências sem Fronteiras (CsF), Idiomas sem Fronteiras (IsF) e Inglês sem Fronteiras (IsF-Inglês).

Outro pressuposto do estudo, sugerido por De Wit (2011), é que a internacionalização do ensino pode ser uma medida para aliviar os efeitos negativos da globalização. No Brasil, Finardi e Prebianca (2014) sugerem que, apesar de haver um esforço por parte do governo federal em estabelecer políticas linguísticas e de internacionalização, as ações não são sistemáticas nem convergentes em todos os níveis educacionais em relação ao ensino de línguas estrangeiras e seu papel no processo de internacionalização.

Essa falta de coerência e sintonia entre as ações, resultados, motivações e processos de internacionalização em todos os níveis da educação pode afetar negativamente o processo de internacionalização ressaltando efeitos nocivos da globalização como a comodificação da educação. A fim de refletir sobre os possíveis efeitos negativos aliados à internacionalização/globalização e à comodificação da educação, este estudo propõe uma reflexão sobre o processo de internacionalização de uma universidade federal do sudeste brasileiro por meio da 
Internacionalização do ensino superior e línguas estrangeiras: evidências de um estudo de caso nos níveis micro, meso e macro

análise desse processo em três níveis, quais sejam: a da comunidade acadêmica, a da instituição e a do governo.

\section{Internacionalização passiva}

Como dito anteriormente, o objetivo desta pesquisa é refletir sobre o processo de internacionalização por meio de um estudo de caso em três níveis como pano de fundo para essa reflexão. Um objetivo secundário do estudo é analisar o papel das línguas estrangeiras em geral e do inglês em particular, no processo de internacionalização. A instituição onde esta pesquisa foi realizada foi escolhida para este estudo por já ter sido objeto de estudos anteriores, revisados no que segue, e que sugerem que essa instituição ainda pertence a um contexto de internacionalização passiva segundo os critérios de Lima e Maranhão (2009).

Finardi e Ortiz (2015) analisaram o curso de graduação em Administração em duas universidades brasileiras, uma pública federal (a mesma onde este estudo foi realizado) e outra privada. Os autores partiram da hipótese de que, à semelhança de IES estrangeiras, as IES públicas e privadas brasileiras deveriam ter diferentes motivações para a internacionalização, sendo que a pública deveria ter uma motivação mais acadêmica enquanto a privada deveria ter uma motivação mais econômica, uma vez que esta última poderia lucrar com as mensalidades de alunos estrangeiros. Outro pressuposto de Finardi e Ortiz (2015) e ainda à semelhança das universidades estrangeiras, é que o curso de Administração deveria ser o curso mais internacionalizado uma vez que a globalização afeta as empresas mais rapidamente do que outras instâncias da produção de conhecimento humano.

Ao analisar o curso de Administração nas duas IES, Finardi e Ortiz (2015) concluíram que: 1) a universidade pública tem motivação acadêmica para a internacionalização, mas esse processo ainda é insipiente e voltado principalmente para a mobilidade do tipo OUT por meio de programas como o Ciência sem Fronteiras (CsF). Os poucos programas de mobilidade do tipo IN identificados em Finardi e Ortiz (2015) são com países que falam português e/ou com universidades que estão classificadas abaixo da universidade investigada no ranque mundial, o que levou Finardi e Ortiz (2015) a aludirem que esses programas são mais conducentes do desenvolvimento de capital social nesses países do que na universidade investigada. Warschauer (2003) define capital social como os benefícios que um indivíduo pode obter por meio de sua ação em redes ou relacionamentos sociais. A segunda conclusão do estudo é que 2) a universidade privada investigada não tem motivação para a internacionalização sendo que os autores explicaram esse resultado inesperado em face do tamanho do mercado interno no 
Brasil, que é tão grande que faz com que universidades privadas não tenham necessidade de buscar recursos (mensalidades) fora do Brasil como é o caso de algumas universidades estrangeiras.

De fato, o Brasil possui 2.391 instituições de ensino superior que oferecem um pouco mais de 32 mil cursos de graduação. Desses, a rede privada participa com mais de $80 \%$ do número de alunos sendo que apenas 301 são de universidades públicas contra 2.090 de instituições privadas.

Finalmente, outra conclusão de Finardi e Ortiz (2015) que interessa a este estudo foi a de que a universidade pública investigada, apesar de motivada para a internacionalização, ainda tinha vários desafios a superar, sendo que o maior deles é a barreira linguística já que a universidade não oferece cursos em ou de inglês na graduação, o que compromete tanto a mobilidade acadêmica do tipo OUT. Nós concordamos com Finardi e Ortiz (2015) que a barreira linguística é talvez a mais alta a ser superada e acrescentamos que para desenvolver a mobilidade do tipo IN é necessário investir também no ensino de outras línguas estrangeiras, principalmente do português como língua estrangeira (PLE).

Em relação ao papel das línguas estrangeiras no processo de internacionalização do Ensino Superior, Finardi, Santos e Guimarães (2016) descrevem a criação de uma Coordenação de Línguas na Secretaria de Relações Internacionais da universidade investigada neste estudo. Segundo esses autores, as línguas estrangeiras têm um papel importantíssimo no desenvolvimento da internacionalização e da mobilidade acadêmica tanto do tipo IN quanto do tipo $O U T$, justificando a criação de uma divisão, dentro da secretaria de relações internacionais, para pensar políticas linguísticas e ações que perpassam o uso e ensino de línguas estrangeiras nessa instituição.

Finardi et al. (2014) analisaram o papel da tecnologia e do ensino de inglês no processo de internacionalização dessa universidade (a mesma investigada no presente estudo) por meio da análise de uma das três principais ações do Programa Inglês sem Fronteiras (IsFInglês) ofertado nessa IES, qual seja, o do curso de inglês online My English Online (MEO). Os autores explicam que o programa IsF-Inglês oferece duas ações à toda a comunidade acadêmica (o curso online e os testes de nivelamento e proficiência TOEFL gratuitamente) e aulas presencias por meio dos Nucli à uma pequena parcela dessa comunidade. No caso da IES investigada e à título de exemplo, a população acadêmica é em torno de 25.000 sendo que apenas 480 vagas são ofertadas a cada ciclo para as aulas presenciais do Nucli. Finardi et al. (2014) concluem que apesar das ações do IsF-Inglês serem relevantes, elas devem ser ofertadas à toda a comunidade acadêmica (e não apenas a uma pequena parcela como é o caso das 
Internacionalização do ensino superior e línguas estrangeiras: evidências de um estudo de caso nos níveis micro, meso e macro

aulas presenciais dos Nucli) e devem se alinhar a políticas linguísticas de base a fim de que os alunos cheguem às universidades já com um melhor nível de proficiência em inglês, garantindo, assim, um processo de internacionalização mais eficaz.

Outro estudo relevante por mostrar o papel do inglês no processo de internacionalização da educação superior é o de Finardi e França (2016), que analisaram a produção e circulação acadêmica nacional em inglês e português da área de Letras. Os autores escolheram a área de Letras por ser essa uma área que historicamente publica mais em português e em livros. Resultados de Finardi e França (2016) mostram que a produção acadêmica em inglês dessa área está muito aquém do desejado para garantir a circulação da produção acadêmica nacional que apesar de ser a 13a maior produção acadêmica do mundo, não tem destaque internacional uma vez que circula em grande parte em círculos restritos à língua portuguesa. Ainda que concordemos com autores que alertam para o viés tendencioso da produção acadêmica internacional bem como para os critérios usados no ranqueamento das melhores universidades (por exemplo HAMEL, 2013), não podemos nos furtar a reconhecer o papel do inglês na circulação da produção acadêmica internacional e na internacionalização do ensino superior.

Finalmente, em relação ao papel dos idiomas estrangeiros na internacionalização do Brasil, Finardi e Archanjo (2015) revisaram políticas linguísticas e programas de internacionalização como o Ciência sem Fronteiras (CsF), o Idiomas sem Fronteiras (IsF) e o Inglês sem Fronteiras (IsF-Inglês) concluindo que o inglês é visto como uma língua estrangeira no ensino primário, onde esse idioma pode ser ensinado, ou não, dependendo da escolha da comunidade escolar. No ensino secundário o inglês ainda é visto como uma língua estrangeira opcional, mas perdendo espaço para o espanhol que ganha destaque. Finalmente, Finardi e Archanjo (2015) concluíram que o papel do inglês no ensino superior é diferenciado do das outras línguas estrangeiras, como mostram os recursos destinados para o programa IsF-Inglês em comparação aos recursos destinados ao IsF. Os resultados da análise de políticas linguísticas e de internacionalização em Finardi e Archanjo (2015) sugerem que, embora o inglês desempenhe o papel de uma língua estrangeira opcional no ensino primário e secundário, esse idioma é visto como língua internacional (FINARDI, 2014) no ensino superior. Finardi e Archanjo (2015) concluem que as políticas linguísticas e de internacionalização têm visões diferentes sobre o papel do inglês e das outras línguas estrangeiras nos diferentes níveis de ensino no Brasil e devem ser alinhadas de modo a permitir uma agenda de internacionalização mais coerente.

O presente estudo parte de resultados e sugestões de Finardi e Ortiz (2015), Finardi, Santos e Guimarães (2016), Finardi et al. (2014), Finardi e França (2016) e Finardi e Archan- 
jo (2015) para analisar o processo de internacionalização dessa universidade em três níveis de organização, quais sejam: o micro, o meso e o macro a fim de entender o papel das línguas estrangeiras e, em especial, do inglês nesses três níveis. Para tanto, partimos de Knight (2004) que propõe uma matriz de análise para a abordagem adotada com relação a ações de internacionalização a nível nacional e institucional para propor nossa análise tridimensional.

Knight (2004) sugere cinco pilares de avaliação para o nível nacional, a saber: (1) programas, (2) análise de princípios e motivações, (3) análise ad hoc, (4) políticas, e (5) estratégias. Em (1) programas, o processo de internacionalização do ensino superior é visto em termos de financiamento de programas que oportunizem a instituições e indivíduos o engajamento em atividades internacionais tais como programas de mobilidade, pesquisa e convênios. $\mathrm{Na}(2)$ análise de princípios e motivações, pensa-se o porquê de o ensino superior ter que se tornar mais internacionalizado. Os princípios e motivações variam muito e podem contemplar o desenvolvimento de recursos humanos, de alianças estratégicas, de transações comerciais, da construção da nação, e do desenvolvimento sociocultural. Já na (3) análise ad hoc, a internacionalização do ensino superior é tratada como ad hoc ou reação à muitas novas oportunidades sendo apresentadas para demandas internacionais, mobilidade, e cooperação no ensino superior. Em (4) políticas, a internacionalização do ensino superior é descrita em termos de políticas que enfatizem a importância de uma dimensão internacional ou intercultural no ensino superior. As políticas podem ser de uma variedade de setores, por exemplo, educação, comércio exterior, ciência e tecnologia, cultura ou negócios. E finalmente em (5) estratégias, a internacionalização é considerada um elemento chave na estratégia nacional para se atingir os objetivos e prioridades de um país tanto nacionalmente quanto internacionalmente.

Já para a abordagem a nível institucional, Knight (2004) apresenta seis pilares de avaliação, a saber: (1) atividade, (2) resultados, (3) princípios e motivações, (4) processo, (5) “em casa/local", e (6) no exterior. No âmbito da (1) atividade, a internacionalização é descrita em termos de atividades tais como intercâmbio no exterior, currículo e programas acadêmicos, convênios institucionais e parcerias, projetos de desenvolvimento, e expansão de campi. Em (2) resultados, a internacionalização é apresentada na forma de resultados esperados em termos de competências dos discentes, desenvolvimento do perfil, acordos internacionais, parcerias e ou projetos. Em termos de (3) princípios e motivações, a internacionalização é pensada de acordo com as motivações principais que a impulsionam. Isso pode incluir padrões acadêmicos, geração de receita, diversidade cultural, desenvolvimento docente e discente. No que diz respeito ao (4) processo, a internacionalização é tida como um processo no qual uma dimensão internacional é integrada às funções de ensino, pesquisa e extensão de uma institui- 
Internacionalização do ensino superior e línguas estrangeiras: evidências de um estudo de caso nos níveis micro, meso e macro

ção. A (5) internacionalização "em casa/local” diz respeito à criação de um clima ou cultura no campus que promova e dê suporte a um entendimento internacional/intercultural e que foque nas atividades do campus. Finalmente, (6) a internacionalização no exterior concerne a difusão da educação para outros países por meio de uma variedade de veículos (presencial, EAD, e-learning) e também por meio de diferentes acordos administrativos tais como franquias, acordos de geminação, e expansão dos campi. A pesquisadora enfatiza ainda que as matrizes que ela propõe são meras referências para que governo e instituições se guiem nos seus processos de internacionalização atuais e futuros, que, ela destaca, dependem dos objetivos desejados por quem os conduzem. Para o escopo deste estudo, consideramos apenas alguns itens da matriz proposta por Knight (2004), quais sejam: a nível micro (institucional), analisamos as respostas dos questionários levando em conta o item "internacionalização em casa/local"; a nível meso (institucional), consideramos as atividades implantadas ou em fase de implementação na universidade; e a nível macro (nacional), observamos as políticas e programas implementados ou em fase de implementação pelo governo federal.

Tendo em vista os resultados desses estudos e da matriz proposta por Knight (2004) e adaptada por nós, o presente trabalho se debruça uma vez mais sobre a questão da internacionalização do ensino superior analisando como ela é interpretada em três níveis diferentes na mesma instituição onde os estudos revisados aqui foram realizados a fim de expandir o conhecimento sobre o processo de internacionalização. Para tanto, o método usado para o estudo é descrito no que segue.

\section{Estudo de Caso}

O estudo é de cunho híbrido (DORNYEI, 2007) analisando qualitativa e quantitativamente dados oriundos de entrevistas, questionários e documentos institucionais e nacionais. A pergunta de pesquisa que motivou o estudo é como a internacionalização é interpretada em três níveis (micro - comunidade acadêmica, meso - instituição e macro - políticas de internacionalização) em uma instituição de ensino superior e qual o papel das línguas estrangeiras em geral e do inglês em particular nesse processo.

Vários instrumentos de coleta de dados foram usados nos três níveis, a saber: micro (questionários, entrevistas), meso (entrevistas, levantamento documental e bibliográfico), macro (levantamento documental e bibliográfico). Um total de 1649 participantes responderam um questionário composto de três questões (Apêndice A) e oito participantes foram entrevistados (Apêndice B) a fim de expandir e aprofundar a compreensão dos dados triangulados 
com os resultados do questionário. Os questionários foram enviados por e-mail e as entrevistas foram realizadas via Skype.

Vale ressaltar que o questionário, criado com o auxílio de uma ferramenta online foi enviado a docentes, discentes, e servidores técnicos-administrativos dos três campi que compõem a universidade investigada. Tínhamos três objetivos principais ao coletar as percepções da comunidade acadêmica sobre o processo de internacionalização nessa instituição, quais sejam: (1) saber quais ações a comunidade acadêmica reconhece como ações de internacionalização, (2) se os participantes se acham incluídos nessas ações, (3) e que tipo de apoio a universidade investigada pode fornecer para que eles estejam incluídos nessas ações.

\section{Contexto Institucional}

A universidade onde o estudo foi realizado é federal e tem três campi localizados estrategicamente em três cidades em um estado da região Sudeste do Brasil. A universidade oferece atividades acadêmicas e de pesquisa em todas as áreas do conhecimento e na data da coleta de dados (2015) contava com 91 cursos de graduação e 60 cursos de pós-graduação (46 mestrados e 14 doutorados). A universidade tem um Centro de Línguas que oferece cursos de português para estrangeiros, bem como cursos de inglês, espanhol, francês, alemão e italiano. Os estudantes internacionais que desejam candidatar-se a cursos de graduação têm que fazer o vestibular. A universidade tem uma Secretaria de Relações Internacionais (SRI), que é responsável pela formulação de políticas de internacionalização e promoção e expansão de ações internacionais que aconselham o reitor, os órgãos centrais da universidade, bem como unidades de ensino e pesquisa. Entre as funções da SRI estão a necessidade de induzir e consolidar o processo de internacionalização, como uma estratégia para o crescimento institucional e a melhoria das atividades acadêmicas; aconselhar todas as unidades acadêmicas relativas à implementação da cooperação internacional; selecionar, preparar e divulgar informações sobre os programas e iniciativas de cooperação internacional; divulgar oportunidades de mobilidade para a comunidade acadêmica; apoiar professores, pesquisadores e alunos de instituições estrangeiras para desenvolver atividades na ou com a universidade; incentivar a implementação de acordos para atividades de pesquisa em colaboração com instituições estrangeiras; manter contato com o Ministério das Relações Exteriores, bem como com as embaixadas, consulados internacionais, organizações e instituições e a promoção de ações cujo objetivo é dar mais visibilidade internacional a nível mundial para a universidade. 
Internacionalização do ensino superior e línguas estrangeiras: evidências de um estudo de caso nos níveis micro, meso e macro

Os estudantes de países da África, América Latina e Caribe que mantêm acordos de cooperação com o Brasil podem participar do Programa de Parceiro alunos de graduação (PEC-G), que é um programa de cooperação entre o Brasil e os países da África, América Latina e do Caribe e cujo objetivo é dar a jovens estudantes destes países a oportunidade de realizar seus estudos de graduação completo em universidades brasileiras.

Em termos de mobilidade de pós-graduação e bolsas de estudo do programa de bolsas PAEC OEA lançado pela Organização dos Estados Americanos (OEA) e universidades brasileiras Grupo Coimbra (GCUB) a instituição conta com o apoio do Ministério da Educação e o Ministério das Relações Exteriores que oferecem 160 bolsas de estudo para mestrado e 19 para doutorado em universidades brasileiras entre os quais está a instituição investigada. $\mathrm{O}$ objetivo do programa é aumentar a mobilidade acadêmica e o desenvolvimento regional das Américas e em sua primeira edição 53 alunos tiveram a oportunidade de ganhar um diploma de mestre no Brasil.

\section{Resultados}

\section{Nível Micro: Percepções da comunidade acadêmica}

A Figura 1 a seguir mostra a distribuição das respostas da comunidade acadêmica da referida universidade no que tange as ações de internacionalização vigentes na IES.

\section{Figura 1 - Percepções da comunidade acadêmica - Ações de Internacionalização}
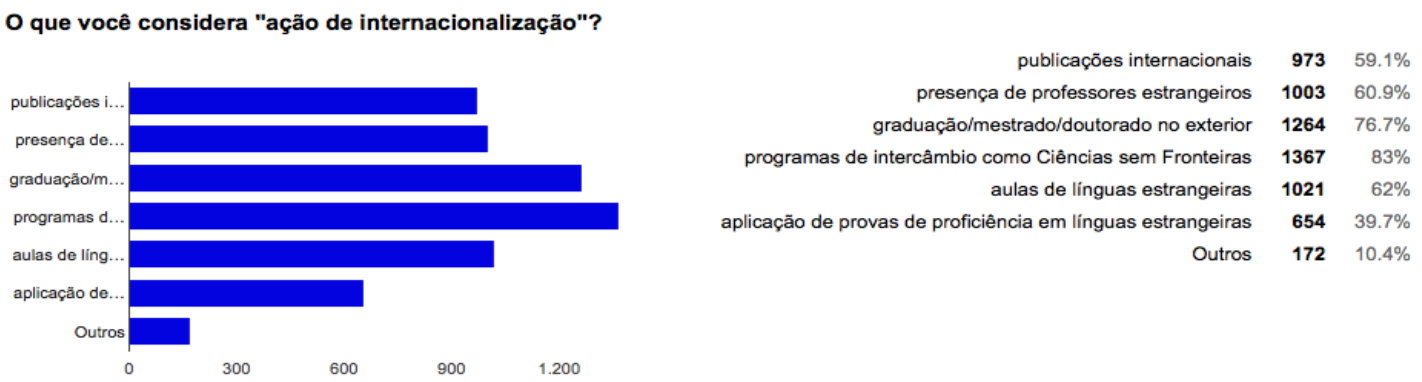

Fonte: Dados de pesquisa dos autores

Com relação às ações de internacionalização, os 1649 respondentes tiveram a opção de marcar quantas opções desejassem, numa gama de sete possibilidades, desde que considerassem aquele item uma ação de internacionalização. Obtivemos, então, as seguintes respostas, conforme pode ser visto na Figura 1 acima: 1367 para programas de intercâmbio como o Ciência sem Fronteiras uma ação de internacionalização; 1264 para graduação, mestrado ou doutorado no exterior; 1021 para aulas de línguas estrangeiras; 1003 para presença de profes- 
sores estrangeiros; 973 para publicações internacionais; 654 para aplicações de provas de proficiência em línguas estrangeiras; e finalmente, 172 para “outros".

Já em relação à inclusão desses indivíduos nas ações propostas pela universidade, recebemos um total de 168 respostas, das quais 72\% (121 respondentes) não se sentem incluídos nas ações em curso na universidade. Em resposta à pergunta aberta, nota-se também que há ainda falta de informação no que venha a ser uma ação de internacionalização. Um exemplo disso é a conexão que os respondentes fazem com a internacionalização e o programa Ciência sem Fronteiras e as aulas de idiomas no Centro de Línguas da universidade. Muitos se dizem excluídos das atividades de internacionalização por não participarem das atividades citadas. De acordo com as entrevistas, há também grande demanda por ações nos campi do interior do estado e não somente na capital. Um dos entrevistados também pediu ações voltadas para área de Humanas.

A Figura 2 mostra o tipo de apoio que a comunidade acadêmica espera receber da IES com relação às ações de internacionalização.

Figura 2 - Percepções da comunidade acadêmica - Apoio da IES

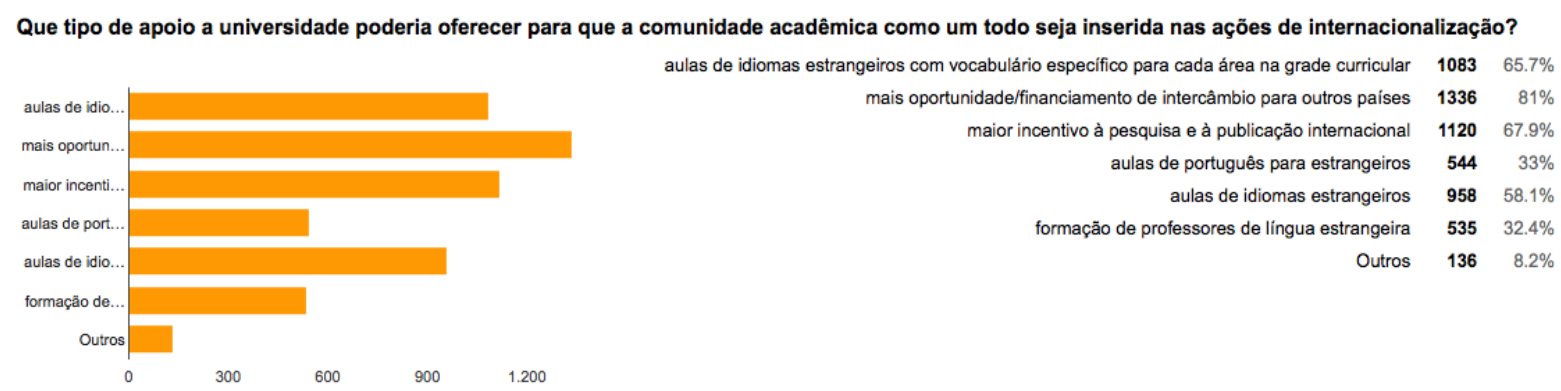

Fonte: Dados de pesquisa dos autores

A grande maioria dos respondentes (1336) espera que a IES promova mais oportunidades e financiamento de programas de intercâmbio internacionais seguido de 1120 que contam com apoio institucional à pesquisa e publicação internacional. Como ilustrado na Figura 2, 1083 respondentes conta com aulas de idiomas estrangeiros com vocabulário específico na própria grade curricular de seus respectivos cursos e, 958 apontam que aulas de idiomas estrangeiros em geral são um desejo da comunidade acadêmica em geral. Aulas de português para estrangeiros (PLE) obteve 544 marcações, seguido de 535 para formação de professores de língua estrangeira. Os dados da análise micro mostram que de forma geral os programas de intercâmbio e os idiomas estrangeiros tem um papel relevante no processo de internacionalização, segundo a percepção da comunidade acadêmica. 
Internacionalização do ensino superior e línguas estrangeiras: evidências de um estudo de caso nos níveis micro, meso e macro

\section{Nível Meso: a instituição}

Seguindo a matriz de análise de Knight (2004), em nível institucional, escolhemos analisar dois aspectos, a saber: (1) programas e (2) atividades. As informações foram coletas no site da Secretaria de Relações Internacionais (SRI) da referida universidade cuja missão é promover e gerir a internacionalização da instituição. Dentre suas atribuições constam: induzir e consolidar a internacionalização na universidade como estratégia de crescimento institucional e de qualificação das atividades acadêmicas; assessorar as diversas unidades acadêmicas da universidade na implementação da cooperação internacional; selecionar, preparar e divulgar informações sobre programas e iniciativas de cooperação internacional; oferecer oportunidades de mobilidade à comunidade da universidade; apoiar docentes, pesquisadores e alunos de instituições estrangeiras em atividades na universidade; fomentar a implementação de convênios para realização de atividades de pesquisa em colaboração com instituições estrangeiras; manter articulação com o Ministério das Relações Exteriores do Brasil, bem como embaixadas, consulados, organizações e instituições internacionais; e promover ativamente ações com o objetivo de dar maior visibilidade à universidade no cenário internacional.

Em termos de programas, a universidade, através de sua SRI, apoia programas do governo ou instituições privadas de mobilidade do tipo IN e $O U T$ em níveis de graduação e pósgraduação bem como para docentes, mas não propõe nenhum programa em si. Dentre os programas de mobilidade do tipo IN e $O U T$ apoiados pela instituição estão: O Programa de Estudantes - Convênio de Graduação (PEC-G), o Programa Ciência sem Fronteiras (graduação), e para a pós-graduação, o Programa de Alianças e Capacitação em Educação - Organização dos Estados Americanos (PAEC-OEA) e o Grupo Coimbra de Universidades Brasileiras (GCUB). Interessados nesses programas encontram informações no site da SRI e a seleção é feita através de editais públicos ou diretamente nos órgãos que organizam os programas. A universidade possui um Núcleo de Idiomas como vertente do programa federal Idiomas sem Fronteiras (Inglês) com aulas presenciais de língua inglesa para alunos da graduação, pós-graduação, técnicos-administrativos e docentes. Os interessados devem fazer a prova de proficiência (TOEFL - Test of English as a Foreign Language) que também é oferecida gratuitamente e periodicamente através de editais públicos pelo governo na instituição.

No que tange às atividades de internacionalização, a universidade, por meio do seu Centro de Línguas, oferece provas de proficiência em língua inglesa (IELTS), francesa (DELF/DALF), italiana, alemã (DAF), e espanhola (DELE) à toda a comunidade acadêmica. 
As provas são oferecidas periodicamente através de editais públicos e parcerias com organizações internacionais e com o Centro de Línguas (CL) da universidade. O CL também oferta um curso de português para estrangeiros (PLE) para alunos e docentes em programas de mobilidade do tipo IN bem como para a comunidade externa. Há também acordos de cooperação internacional com países da América do Norte e Latina e Europa, sendo a maior parte deles concentrada em países europeus e norte-americanos.

\section{Nível Macro: Políticas nacionais de internacionalização das universidades}

A Secretaria de Educação Superior (SESu), de acordo com pesquisa feita no sítio eletrônico da instituição, é a unidade do Ministério da Educação (MEC) responsável por "planejar, orientar, coordenar e supervisionar o processo de formulação e implementação da Política Nacional de Educação Superior. A manutenção, a supervisão e o desenvolvimento das instituições públicas federais de ensino superior (Ifes) e a supervisão das instituições privadas de educação superior, conforme a Lei de Diretrizes e Bases da Educação Nacional (LDB), também são de responsabilidade da SESu”. No âmbito das instituições de ensino superior (IES), a SESu responde, portanto, por todo o planejamento e execução das políticas nacionais de educação, incluindo as que tangem o processo de internacionalização das IES.

Dando prosseguimento à análise segundo a matriz de Knight (2004), atualmente, a SESu juntamente com a Coordenação de Aperfeiçoamento Pessoal de Nível Superior (CAPES) coordenada o programa Idiomas sem Fronteiras (IsF) e o Programa Inglês sem Fronteiras (IsF-Inglês) que oferece aulas de inglês gratuitas nos campi das universidades públicas federais e estaduais. Segundo o sítio eletrônico do programa, o objetivo principal do IsF é "incentivar o aprendizado de línguas, além de propiciar uma mudança abrangente e estruturante no ensino de idiomas estrangeiros nas universidades do País". O IsF-Inglês foi lançado em 2012 para, inicialmente, melhorar o nível de proficiência em inglês dos candidatos do programa Ciência sem Fronteiras $(\mathrm{CsF})$ e outros programas de mobilidade estudantil, também apoiados pelo governo federal, mas logo se tornou um dos principais programas de internacionalização do governo. Em dezembro de 2014 o programa foi expandido para incluir outros idiomas e rebatizado de Idiomas sem Fronteiras (IsF). No segundo semestre de 2015, o IsF esteve presente em todas as universidades federais do Brasil sendo que o IsF-Inglês ofertou o curso de inglês online (MEO) e as provas de proficiência (TOEFL) à toda a comunidade acadêmica e aulas de inglês presenciais por meio dos Nucli a uma pequena parcela da comunidade acadêmica e mediante editais próprios. O IsF lançou editais para o francês e planeja lançar 
Internacionalização do ensino superior e línguas estrangeiras: evidências de um estudo de caso nos níveis micro, meso e macro

editais para outros idiomas, à semelhança do que é feito no inglês por meio dessas três ações principais (curso online, provas de proficiência e aulas presenciais), porém não na mesma proporção do que é feito atualmente com o inglês.

O Programa Ciência sem Fronteiras (CsF) busca fomentar a capacitação de indivíduos com vistas à internacionalização, permitindo o acesso a instituições de ensino superior e centros de pesquisa estrangeiros de excelência. Em sua primeira versão, o programa contava com as seguintes modalidades de bolsas: graduação sanduíche no exterior, doutorado sanduíche no exterior, doutorado no exterior, atração de jovens talentos, pós-doutorado no exterior, pesquisador visitante especial e mestrado no exterior.

Devido à crise político-econômica que atingiu o Brasil em meados de 2014, o programa Ciência sem Fronteiras está sendo repaginado e deve voltar em novo formato, buscando atender alunos de pós-graduação de variados cursos (incluindo ciências humanas e artes), desde que tais alunos sejam escolhidos por universidades estrangeiras renomadas. Os gestores do programa também estudam a possibilidade de ampliar o programa para oferecer a alunos do Ensino Médio (EM) a chance de realizar cursos de idiomas de curta duração, no exterior, durante o período de férias. Estudantes de graduação, os maiores beneficiados pelas primeiras versões do programa, não seriam incluídos no novo formato, devido ao elevado custo de manutenção das bolsas nessa modalidade.

Segundo Finardi (2016), o programa Idiomas sem Fronteiras Fronteiras (IsF) é um desdobramento direto do programa Inglês sem Fronteiras (IsF-Inglês), que por sua vez é um desdobramento indireto do programa CsF. Dois anos após o lançamento do IsF-Inglês, esse programa já tinha tomado uma dimensão muito maior daquele da sua criação destacando-se de sua origem para adquirir uma agenda própria que tem estimulado e promovido o debate sobre políticas linguísticas no Brasil.

Em razão da reforma do Ensino Médio (EM) prevista pela MP 746, que prevê o ensino de inglês como sendo obrigatório, além da previsão de adaptação do programa CsF para esse nível de escolaridade, é possível prever que as ações dos programas de internacionalização propostos pelo Governo Federal continuem a concentrar a maior parte dos recursos na mobilidade estudantil do EM e na oferta de ações voltadas para o ensino de inglês. A análise dos programas CsF e IsF feita por Finardi e Archanjo (2015), sugere que esses programas resistiram ao escrutínio público e às crises políticas e econômicas no Brasil. Entretanto e apesar dos louváveis benefícios trazidos por esses programas ao Brasil, podemos dizer que nossa política de internacionalização ainda é passiva (LIMA; MARANHÃO, 2009), concentrando esforços no envio de acadêmicos a universidades hegemônicas e ao desenvolvimento da mobilidade do 
tipo $O U T$ e finalmente, que as políticas linguísticas e de internacionalização ainda não estão sendo pensadas de forma ativa e integrada em todos os níveis educacionais e essa realidade nacional não é diferente da encontrada na instituição investigada, como veremos na discussão que segue.

\section{Discussão}

A fim de termos uma ideia do alcance das ações do Programa IsF-Inglês na IES investigada, e como já revisado por Finardi et al. (2014), as ações do IsF-Inglês são basicamente três, sendo que apenas duas são ofertadas a todas a comunidade acadêmica: a oferta de um curso online (My English Online) e provas TOEFL sendo que a oferta de cursos presenciais por meio dos Nuclis são para apenas uma pequena porcentagem da comunidade acadêmica de cada IES. No caso da IES investigada que tem em torno de 25000 integrantes, a oferta do Nucli se limita a 480 vagas a cada período, ou seja, as aulas presenciais são ofertadas a menos de $2 \%$ da população acadêmica. Assim, concordamos com Finardi et al. (2014) que a fim de possibilitar um melhor processo de internacionalização as ações de programas de internacionalização como o IsF-Inglês devem ser expandidas à toda a comunidade universitária e devem se alinhar a políticas linguísticas de base a fim de garantir um melhor nível de proficiência em inglês aos que ingressam nas universidades. Percebe-se que muito embora a comunidade acadêmica da IES investigada se encontre engajada e interessada em programas de mobilidade, há também grande interesse em cursos de idiomas, demanda ainda em defasagem no programa IsF.

Em relação ao papel das línguas estrangeiras em geral e do inglês em particular, Finardi (2014) sugere que uma possibilidade para garantir o acesso universal ao ensino de inglês no Brasil seria alterar o seu status de língua estrangeira para o de língua internacional, sendo ensinada obrigatoriamente na Educação Básica de forma alinhada com políticas de internacionalização e sem prejuízo do ensino de outras línguas estrangeiras cuja escolha continuaria à critério de cada comunidade escolar, conforme preconiza a lei maior de Educação brasileira (Lei de Diretrizes e Bases da Educação). Ainda segundo Finardi (2014), essa alteração no status e política de ensino do inglês teria a vantagem de reduzir a lacuna social criada pela oferta desse idioma em institutos particulares fazendo com que apenas uma certa parcela da população tenha acesso a seu ensino. Essa seria também uma medida eficiente para combater os possíveis efeitos negativos aliados à globalização, como o da comodificação da educação, neste caso, do ensino de inglês. Certamente essa mudança no status e política de ensino do 
Internacionalização do ensino superior e línguas estrangeiras: evidências de um estudo de caso nos níveis micro, meso e macro

inglês teria efeitos retroativos na formação docente, como já sugerido por Finardi e Prebianca (2014) que analisaram a formação docente em relação à internacionalização nessa mesma instituição.

Nota-se que há um movimento nessa direção apontada por Finardi et al. (2014), uma vez aprovada a MP 746 que institui o ensino de inglês obrigatório no ensino básico e a repaginação do programa CsF para contemplar alunos do Ensino Médio. Tais medidas entram em confluência com as ações de internacionalização propostas no ensino superior visto que instituem o ensino de língua inglesa como prática necessária e valiosa à internacionalização do ensino e, mais importante, ao acesso à informação em tempos de globalização.

Finalmente, concordamos com Finardi e Archanjo (2015) que o investimento realizado até o momento no inglês e nos outros idiomas pelos Programas IsF e IsF-Inglês mostra claramente que o inglês tem um papel de destaque em relação às outras línguas estrangeiras no processo de internacionalização do ensino superior. Em razão dessa diferença, Finardi e Archanjo (2015) sugerem, e nós concordamos, que é necessário haver um afinamento entre políticas de internacionalização e políticas linguísticas. Os dados levantados e analisados no presente estudo corroboram todas essas sugestões e mostram que temos um longo caminho a percorrer para garantir um processo de internacionalização mais eficiente e coerente.

O ensino de idiomas em geral e do inglês em particular, figura-se de suma importância para o planejamento de atividades de internacionalização do ensino superior como, por exemplo, o incentivo à publicação internacional e a presença de docentes estrangeiros, sugestões dadas pelos participantes da pesquisa conduzida neste estudo. Uma das grandes críticas do programa $\mathrm{CsF}$ foi o fato de os participantes não possuírem a proficiência exigida pelas universidades recipientes e o grande gasto do governo com a preparação linguística desses alunos no exterior (ARCHANJO, 2016). Com as novas medidas em escala macro (nacional), espera-se que os alunos ingressantes das IES tenham um nível de proficiência melhor do que o quadro atual. Dessa forma, o processo de internacionalização do ensino superior poderá passar de uma internacionalização tipicamente passiva para uma internacionalização mais ativa e, portanto, que possa contribuir de forma mais igualitária às demandas das universidades no mundo todo.

\section{Conclusão}

O presente estudo teve como objetivo refletir sobre o processo de internacionalização das universidades brasileiras e sobre o papel das línguas estrangeiras em geral e do inglês em 
particular nesse processo. Para tanto, foi realizada uma análise de aspectos micro, meso e macro da internacionalização de uma instituição de ensino superior dentro de três esferas concêntricas, quais sejam: a da comunidade acadêmica, a da instituição e a do governo. Resultados da análise macro sugerem que a internacionalização afeta e é afetada pela globalização e pelo papel do inglês na circulação da produção acadêmica. O estudo sugeriu ainda, que a fim de evitar possíveis efeitos negativos da globalização como a comodificação da educação e o aumento da lacuna social por meio da terceirização/privatização do ensino de inglês, o papel desse idioma deve ser revisto e equacionado por políticas linguísticas e de internacionalização. A análise meso sugere que a instituição investigada almeja a internacionalização que ainda é insipiente e cheia de desafios, dentre os quais talvez o maior seja a falta de proficiência no inglês. Finalmente, a análise micro sugere que a comunidade acadêmica está interessada no processo de internacionalização e percebe a relevância dos programas de internacionalização e das línguas estrangeiras, mas ainda não está plenamente engajada no mesmo, talvez pela falta de sintonia entre os três níveis de política e de ações de internacionalização. O estudo conclui que as línguas estrangeiras em geral e o inglês em particular são essenciais para o pleno desenvolvimento do processo de internacionalização que, conforme se pode perceber na análise dos programas CsF e IsF, ainda é limitado e desarticulado de outras políticas linguísticas e educacionais de base.

\section{Referências}

ARCHANJO, Renata. Moving globally to transform locally? Academic mobility and language policy in Brazil. Language Policy, Nova Iorque, p. 1-22, Julho, 2016.

BIANCHETTI, Lucídio; MAGALHÃES, António M. Declaração de Bolonha e internacionalização da educação superior: protagonismo dos reitores e autonomia universitária em questão. Avaliação, Campinas; Sorocaba, v. 20, n. 1, p. 225-249, 2015.

BLOMMAERT, Jan. The Sociolinguistics of Globalization. Cambridge Approaches to Language Contact, Nova Iorque, 2010. p. 214.

DE WIT, Hans. Globalization and Internationalisation of Higher Education. Revista de Universidad y Sociedad del Conocimiento, Barcelona, v. 8, n. 2, p. 241-248, 2011.

DORNYEI, Zoltán. Research methods in applied linguistics: quantitative, qualitative, and mixed methodologies. Oxford: Oxford University Press. 2007.

FINARDI, Kyria Rebeca. Globalization and English in Brazil. In: FINARDI, Kyria Rebeca. (Org.). English in Brazil: views, policies and programs. Londrina: EDUEL, 2016. v. 1, p. 1536.

FINARDI, Kyria Rebeca. The slaughter of Kachru's five sacred cows in Brazil and the use of English as an international language. Studies of English Language Teaching, Nova Iorque, v. 2, p. 401-411, 2014. 
Internacionalização do ensino superior e línguas estrangeiras: evidências de um estudo de caso nos níveis micro, meso e macro

FINARDI, Kyria Rebeca; ARCHANJO, Renata. Reflections on internationalization of education in Brazil. In: INTERNATIONAL BUSINESS AND EDUCATION CONFERENCE, 2015, Nova Iorque. International Business and Education Conference Proceedings. Nova Iorque: Clute Institute, 2015. v. 1. p. 504-510.

FINARDI, Kyria; FRANÇA, Claudio. O inglês na internacionalização da produção científica brasileira. Intersecções, Jundiaí, v. 19, p. 234-250, 2016.

FINARDI, Kyria Rebeca; ORTIZ, Ramon Andrés. Globalization, Internationalization and Education: What is the Connection? IJAEDU- International E-Journal of Advances in Education, Nova Iorque, v. 1, p. 18-25, 2015.

FINARDI, Kyria Rebeca; PREBIANCA, Gicele. Políticas linguísticas, internacionalização, novas tecnologias e formação docente: um estudo de caso sobre o curso de Letras Inglês em uma universidade federal. Leitura (UFAL), Alagoas, v. 1, p. 129-154, 2014.

FINARDI, Kyria Rebeca; PREBIANCA, Gicele; SCHMITT, Jeovani; ANDRADE, D. F. Technology, english language teaching and internationalization at a crossroad: Insights from the analysis of a virtual learning environment in Brazil.. In: INTERNATIONAL CONFERENCE OF EDUCATION, RESEARCH AND INNOVATION, 2014, Sevilha. ICERI2014 Proceedings. Madri: IATED, 2014. v. 1. p. 1-12.

FINARDI, Kyria Rebeca; SANTOS, Jane M.; GUIMARAES, Felipe. A relação entre línguas estrangeiras e o processo de internacionalização: evidências da coordenação de letramento internacional de uma Universidade Federal. Interfaces Brasil/Canadá, Pelotas, v. 16, p. 233255, 2016.

HAMEL, Rainer Enrique. L'anglais, langue unique pour les sciences? Le rôle des modèles plurilingues dans la recherche, la communication scientifique et l'enseignement supérieur. Synergies Europe, Sylvains les Moulins, França, n. 8, 2013.

KNIGHT, Jane; DE WIT, Hans. (Eds). Internationalization of higher education in Asia Pacific countries. Amsterdam: European Association for International Education, 1997.

KNIGHT, Jane. Updated internationalization definition. International Higher Education, Ontário, Canadá, v. 33, p. 2-3, 2003.

KNIGHT, Jane. Internationalization remodeled: definition, approaches, and rationales. Jornal of Studies in International Education, Ohio, v. 8, n. 1, p. 5-31, 2004.

LEITE, Denise; GENRO, Maria Erly Herz. Avaliação e internacionalização da educação superior: Quo vadis América Latina. Avaliação, Campinas; Sorocaba, v. 17, n. 3, 2012.

LIMA, Manolita Correia; MARANHÃO, Carolina Machado Saraiva de Albuquerque. O sistema de educação superior mundial: entre a internacionalização ativa e passiva. Avaliação, Campinas; Sorocaba, v. 14, n. 3, p. 583-610, 2009.

LUCE, Maria Beatriz; FAGUNDES, Caterine Vila; GONZÁLEZ MEDIEL, Olga.

Internacionalização da educação superior: a dimensão intercultural e o suporte institucional na avaliação da mobilidade acadêmica. Avaliação, Campinas; Sorocaba, v. 21, n. 2, p. 317-339, jul. 2016.

SEGRERA, Francisco López. Educación superior comparada: tendencias mundiales y de América Latina y Caribe. Avaliação, Campinas; Sorocaba, v. 21, n. 1, 2015.

VARGHESE, Naduvilaparambil. Globalization and higher education: Changing trends in cross border education. Analytical Reports in International Education, La Jolla, Califórnia, v. 5. n. 1, p. 7-20. 2013. 
WARSCHAUER, Mark. Social capital and access. Universal Access in the Information Society, Nova Iorque, v. 2, n. 4, 2003.

\title{
APÊNDICE A- Questionário
}

\author{
Internacionalização na IES (nome da IES omitido para manter anonimato) \\ O que você considera uma "ação de internacionalização"? \\ - Publicações internacionais \\ - Presença de professores estrangeiros \\ - Graduação/mestrado/doutorado no exterior \\ - Programas de intercâmbio como Ciências sem Fronteiras \\ - Aulas de línguas estrangeiras \\ - Aplicação de provas de proficiência em línguas estrangeiras \\ - Outro:
}

Você se considera incluído(a) nas ações de internacionalização propostas pela universidade? Explique sua resposta.

Que tipo de apoio a universidade poderia oferecer para que a comunidade acadêmica como um todo seja inserida nas ações de internacionalização?

Marque as alternativas relevantes para você.

- Aulas de idiomas estrangeiros com vocabulário específico para cada área na grade curricular

- Mais oportunidade/financiamento de intercâmbio para outros países

- Maior incentivo à pesquisa e à publicação internacional

- Aulas de português para estrangeiros

- Aulas de idiomas estrangeiros

- Formação de professores de língua estrangeira

- Outro:

\section{APÊNDICE B - Entrevista}

Obrigado pelo interesse em participar da nossa pesquisa. Sua colaboração nos ajudará a pensar e propor ações de internacionalização na nossa universidade. Favor responder as duas perguntas a seguir.

1. Quais ações de internacionalização ou melhorias nas ações já existentes você sugeriria para a IES (nome da IES omitido)?

2. Quais vantagens que você listaria em participar dessas ações de internacionalização na IES (nome da IES omitido)?

Gabriel Brito Amorim - Universidade Federal do Espírito Santo Vitória |ES | Brasil. Contato: gabrielbamorim@gmail.com

Kyria Rebeca Finardi - Universidade Federal do Espírito Santo Vitória |ES | Brasil. Contato: kyria.finardi@gmail.com 